\title{
Angiotensin Inhibition Potentiates the Renal Responses to Neutral Endopeptidase Inhibition in Dogs with Congestive Heart Failure
}

Kenneth B. Margulies, Mark A. Perrella, Linda J. McKinley, and John C. Burnett, Jr. Cardiorenal Research Laboratory, Departments of Internal Medicine and Physiology,

Mayo Clinic and Foundation, Rochester, Minnesota 55905

\begin{abstract}
The renal natriuretic actions of endogenous atrial natriuretic factor are enhanced by neutral endopeptidase inhibition (NEPI). Recognizing that activation of the renin-angiotensin-aldosterone system in congestive heart failure (CHF) antagonizes the renal actions of atrial natriuretic factor, we hypothesized that angiotensin II antagonism with converting enzyme inhibition would potentiate the renal actions of NEP-I in CHF. To test this hypothesis, the renal responses to a specific NEP-I (SQ 28,603 ) were assessed in dogs with eight days of experimental CHF produced by rapid ventricular pacing. The renal natriuretic responses to NEP-I in experimental CHF were significant. In the same model of $\mathrm{CHF}$, chronic angiotensin antagonism with converting enzyme inhibition potentiated both renal hemodynamic and excretory responses to NEP-I. The potentiated renal hemodynamic response included significant increases in glomerular filtration rate and filtration fraction. In the CHF group with angiotensin antagonism, an intrarenal infusion of low-dose angiotensin abolished the potentiated renal responses to NEP-I, supporting the concept that intrarenal angiotensin antagonism, rather than improved systemic hemodynamics or potentiation of other peptide systems, mediated the enhanced renal responses to NEP-I in the presence of converting enzyme inhibition. (J. Clin. Invest. 1991. 88:1636-1642.) Key words: converting enzyme inhibition • sodium excretion • renal hemodynamics $\bullet$ atrial natriuretic factor $\bullet$ rapid ventricular pacing
\end{abstract}

\section{Introduction}

Atrial natriuretic factor (ANF) ${ }^{1}$ is a peptide hormone of cardiac origin with multiple biologic effects including natriuresis, diuresis, vasodilation, and inhibition of renin and aldosterone secretion. Among pathophysiologic states associated with ele-

This study was presented in part at the American Society of Nephrology's 23rd annual meeting, Washington, DC, 2-5 December 1990, and was published in abstract form in 1990. (JASN [J.Am. Soc. Nephrol.]. 1:420.)

Address correspondence to Kenneth B. Margulies, M.D., Cardiorenal Research Laboratory, Mayo Clinic and Foundation, 200 First Street SW, Rochester, MN 55905.

Received for publication 9 January 1991 and in revised form 5 June 1991.

1. Abbreviations used in this paper: $\mathrm{AII}$, angiotensin II; CEI, converting enzyme inhibition; CHF, congestive heart failure; Dist FRNa, distal fractional reabsorption of sodium; FF, filtration fraction; GFR, glomerular filtration rate; NEP-I, neutral endopeptidase inhibition; P1 ANF, plasma atrial natriuretic factor; Prox FRNa, proximal fractional sodium reabsorption; RAAS, renin-angiotensin-aldosterone system; $\mathrm{UNaV}$, absolute sodium excretion.

The Journal of Clinical Investigation, Inc.

Volume 88, November 1991, 1636-1642 vated circulating ANF, some of the highest levels are seen in humans and animals with congestive heart failure (CHF) (1). However, several studies (2-7) have demonstrated a blunted renal response to exogenous ANF in CHF. Multiple mechanisms have been implicated in this blunted renal response to ANF in CHF including: changes in ANF receptor density (8$10)$, enhanced degradation and clearance of $\operatorname{ANF}(11,12)$, altered postreceptor signal transduction (13), activation of counterregulatory neurohumoral systems $(14,15)$, and decreased renal perfusion pressure (5). These mechanisms are not mutually exclusive.

Accumulating evidence suggests that activation of the renin-angiotensin-aldosterone system (RAAS) in part contributes to sodium retention in CHF and renal resistance to ANF in this sodium avid state. In fact, previous studies have demonstrated antagonism between the RAAS and ANF with respect to both renal hemodynamics and tubular sodium handling (16, 17). In general, ANF promotes sodium excretion and vasorelaxation while angiotensin II (AII) promotes sodium retention and vasoconstriction. Moreover, in a recent study by Raya et al. (18) AII inhibition with a converting enzyme inhibitor enhanced hemodynamic responsiveness to ANF in rats with $\mathrm{CHF}$, and a preliminary report indicates that AII inhibition restored the natriuretic response to infused ANF in dogs with high-output CHF (15). In contrast, one recent study failed to demonstrate an association between RAAS activation and ANF resistance (19). Thus, most available evidence suggests that activation of the RAAS antagonizes the renal actions of $\mathrm{ANF}$ in CHF.

ANF is degraded in vitro and in vivo by neutral endopeptidase (12, 20-22). Recent studies from our laboratory have demonstrated that neutral endopeptidase inhibition (NEP-I) potentiates the renal action of both physiologic and pathophysiologic levels of ANF in normal anesthetized dogs (22) and dogs with experimental CHF (12). While these results suggest a potential therapeutic role of NEP-I, the effects of NEP-I, like ANF itself, may be attenuated by activation of the RAAS in the setting of severe CHF. Therefore the current studies were designed to test the hypothesis that chronic inhibition of AII generation in dogs with experimental $\mathrm{CHF}$ will potentiate the renal effects of NEP-I. To test this hypothesis, the renal responses to a specific NEP-I (SQ 28,603) were assessed in dogs with eight days of experimental CHF. AII inhibition was achieved with five days of low dose oral converting enzyme inhibition (CEI) with captopril. To further define the role of AII in modulating the renal action of NEP-I, exogenous AII was administered intrarenally into one kidney of captopril treated dogs receiving acute NEP-I.

\section{Methods}

Surgical preparation. Experiments were performed on two groups of six male mongrel dogs weighing between 15 and $24 \mathrm{~kg}$ and maintained 
on a fixed sodium intake of $100 \mathrm{mEq} / \mathrm{d}$. All studies conformed to the guiding principles of the American Physiological Society. Experimental CHF was produced by ventricular pacing at 240 beats per min for 8 $\mathrm{d}$ before acute interventions. This experimental model has been shown consistently to produce a state of low output cardiac failure with the constellation of cardiac, renal, and neurohormonal abnormalities characteristic of chronic primary myocardial dysfunction $(23,24)$. In particular, this model is characterized by marked increases in circulating ANF and activation of the RAAS in association with avid sodium retention.

Programmable pacemakers (model 8426; Medtronic Inc., Minneapolis, MN) were implanted $6 \mathrm{~d}$ before the start of pacing. Under pentobarbital anesthesia and via a left thoracotomy and pericardiectomy, the heart was exposed and a screw-in epicardial pacemaker lead was implanted into the right ventricular apex. The pacemaker lead was connected to a pulse generator implanted subcutaneously on the chest. The pericardium was sutured closed, and the parietal pleura and skin were closed in layers. The dogs were then allowed to recover over a 5-d period, the first $3 \mathrm{~d}$ of which they received prophylactic antibiotic treatment with clindamycin and Combiotic ${ }^{\circledR}$ (Pfizer, Inc., New York, NY). $5 \mathrm{~d}$ after pacemaker implantation, the pacemakers were programmed to 240 beats per min and pacing continued for the remainder of the experiment. In group II, inhibition of AII generation with captopril $12.5 \mathrm{mg}$ three times daily (Bristol-Myers-Squibb, Inc., Princeton, NJ) commenced $3 \mathrm{~d}$ after the initiation of pacing. All dogs were given lithium carbonate $300 \mathrm{mg}$ orally and fasted $16-20 \mathrm{~h}$ before the acute experiment. Dogs were permitted to drink water ad lib. until the time of the experiments.

On the ninth day of pacing, dogs were anesthetized using fentanyl $(0.005-0.01 \mathrm{mg} / \mathrm{kg})$ and sodium pentobarbital $(5-10 \mathrm{mg} / \mathrm{kg}$ intravenously). Supplemental $30-\mathrm{mg}$ doses of pentobarbital were given as needed during the experiment. The animals were intubated and mechanically ventilated (Harvard respirator; Harvard Apparatus, Millis, MA) with supplemental oxygen at 4 liters/min. A femoral artery was cannulated for monitoring of arterial pressure and blood sampling. Femoral veins were cannulated for infusion of inulin and injection of the NEP-I and supplemental anesthetic. A balloon-tipped, flow-directed pulmonary artery catheter (model 93A-131-7F; American Edwards Laboratories, AHS del Caribe, Inc., Anasco, Puerto Rico) was placed via the right internal jugular vein for measurement of cardiac filling pressures and determination of cardiac output.

A flank incision was performed to gain exposure to the left kidney in all groups. The ureter was cannulated for urine collection and a noncannulating electromagnetic flow probe (Carolina Medical Electronics, Inc., King, NC) was placed around the renal artery for online measurement of renal blood flow. In group II, bilateral flank incisions were performed and both kidneys instrumented as described above. In addition, in all kidneys studied, curved 23-gauge needles, attached to polyvinyl tubing, were inserted into each renal artery distal to the flow probe and were kept patent by an infusion of $0.9 \%$ saline at $0.5 \mathrm{ml} / \mathrm{min}$.

Experimental protocol. A priming dose of inulin was given, and a constant infusion of $1 \mathrm{ml} / \mathrm{min}$ was begun in an effort to achieve a steady-state plasma level of $40-60 \mathrm{mg} / \mathrm{dl}$. Following a 60 -min equilibration period, a sample of arterial blood was drawn for baseline hormonal analysis. In group II an intrarenal infusion of AII $(1.5 \mathrm{ng} / \mathrm{kg}$ per min, Sigma Chemical Co., St. Louis, MO) was initiated into the right renal artery while the contralateral kidney and the instrumented kidney in group I received the saline vehicle at the same rate $(0.5 \mathrm{ml} / \mathrm{min})$. The dose of AII was selected to produce pathophysiologic levels of AII in the supplemented kidney without affecting systemic hemodynamics or renal function in the contralateral kidney (16). After a 15-min lead in period, 30-min "pre-NEP-I" renal clearances were performed for all kidneys. During this and subsequent clearance periods, blood was drawn for hormonal analyses and determination of inulin, sodium, and lithium concentrations. Cardiac output, mean arterial pressure, right and left atrial pressure, renal blood flow, and urine flow were also measured during each clearance period. Additional urine samples were collected on ice for measurement of urinary ANF and urinary cGMP.

At the conclusion of the pre-NEP-I clearance period, in all groups the NEP-I (SQ 28,603, Bristol-Myers-Squibb, Inc.) was given intravenously over $2 \mathrm{~min}$ at a dose of $30 \mathrm{mg} / \mathrm{kg}$ dissolved in $20 \mathrm{ml}$ of $0.83 \%$ sodium bicarbonate solution. SQ 28,603 ( $N$-[2-(mercaptomethyl)-1oxo-3-phenylpropyl]- $\beta$-alanine) is a potent competitive inhibitor of neutral endopeptidase 24.11 with a $K_{\mathrm{i}}$ value of $1 \mathrm{nM}$. SQ 28,603 is selective in that it demonstrates only weak activity against other renal brush border peptidases such as angiotensin converting enzyme $\left(I_{50}\right.$ $=32 \mu \mathrm{M})$ and aminopeptidase $\mathrm{M}$ in which there was no inhibition at concentrations up to $1 \mu \mathrm{M}$ (Dalaney, N. G., unpublished data). Two additional 30-min clearance periods were performed beginning $15 \mathrm{~min}$ after the NEP-I was given. In all experiments, urinary fluid losses were replaced with intravenous normal saline every $15 \mathrm{~min}$.

Analysis. Cardiac output was determined by thermodilution (Cardiac Output model 9510-A computer; American Edwards Laboratories, Irvine, CA), measured in quadruplicate and averaged during each clearance period. Pulmonary capillary wedge pressure was used to determine left atrial pressure and right atrial pressure was measured directly. Systemic vascular resistance was calculated by dividing cardiac output by the difference between mean arterial and right atrial pressures. All voided urine was collected on ice, measured using a graduated cylinder, and aliquoted for measurement of sodium, inulin, lithium, ANF, and cGMP concentrations. Urine samples for ANF analysis were stored at $-20^{\circ} \mathrm{C}$ until assay. Urine samples for cGMP determination were heated to $>90^{\circ} \mathrm{C}$ to eliminate phosphodiesterase activity and stored at $-20^{\circ} \mathrm{C}$ until analysis.

Blood for sodium, creatinine, and lithium determination was collected in heparinized tubes, placed on ice, and centrifuged at $2,500 \mathrm{rpm}$ at $4^{\circ} \mathrm{C}$. After centrifugation, plasma was separated and refrigerated until analysis. Glomerular filtration rate (GFR) was determined by inulin clearance. Plasma and urine inulin concentrations were determined by the anthrone method (25). To calculate renal filtration fraction, GFR was divided by renal plasma flow. Plasma and urinary sodium concentrations were measured using ion-selective electrodes (Beckman Instruments, Brea, CA), and plasma and urine lithium levels were determined by flame-emission spectrophotometry (model 357 ; Instrumentation Laboratory, Inc., Lexington, MA). Proximal fractional sodium reabsorption (Prox FRNa) was calculated using the formula: Prox FRNa $(\%)=[1-(\mathrm{Li}$ clearance/inulin clearance $)] \times 100$. Distal fractional reabsorption of sodium (Dist FRNa) was calculated using the formula: Dist FRNa (\%) $=[(\mathrm{Li}$ clearance-Na clearance $) /(\mathrm{Li}$ clearance)] $\times 100$.

Blood for hormone analysis was placed in EDTA tubes, immediately placed on ice, and centrifuged at $2,500 \mathrm{rpm}$ at $4^{\circ} \mathrm{C}$. Plasma was separated and stored at $-20^{\circ} \mathrm{C}$ until assay. Extracted arterial plasma levels of ANF and urinary ANF were measured by radioimmunoassay to $\alpha$-hANF as previously described (1). Plasma renin activity was determined by radioimmunoassay using the method of Haber et al. (26). Plasma aldosterone concentration was measured by specific radioimmunoassay (27). Plasma samples for cGMP were extracted with ethanol. Plasma and urinary cGMP were measured by radioimmunoassay using the method of Steiner (28). Fractional excretion of ANF was calculated by dividing the urinary clearance of ANF by the urinary clearance of inulin. Net renal generation of cGMP, a measure of nephrogenous cGMP production, was determined using the formula: Net renal generation of $\mathrm{CGMP}=$ (urinary $\mathrm{cGMP} \times$ urine flow rate) - (plasma cGMP $\times$ GFR).

All data are presented as mean \pm standard error. Within each group, comparisons with baseline were made using analysis of variance for repeated measures followed by Dunnett's $t$ test when appropriate. Comparisons between groups were analyzed by one-way analysis of variance followed by Fisher's least significant difference test when appropriate. Comparisons of absolute changes after NEP-I between kidneys in group II were analyzed by paired Student's $t$ test. Statistical significance was defined as $P<0.05$.

\section{Results}

At baseline, before initiation of intrarenal infusions, plasma renin activity was moderately but significantly increased in the 
captopril-treated group $(n=6)$ compared with untreated controls $(n=6)$ as illustrated in Fig. 1. The systemic hemodynamic and hormonal parameters for the two experimental groups before and after NEP-I administration are presented in Table I. In the pre-NEP-I period, mean plasma ANF levels were lower with inhibition of AII generation in group II, yet plasma cGMP levels did not differ between the two groups.

Renal hemodynamic and excretory parameters for the two experimental groups before and after NEP-I administration are presented in Table II. Before NEP-I administration, there were no significant differences in renal hemodynamic or excretory function between the CHF groups with and without inhibition of AII generation.

In CHF with NEP-I alone (group I), the only significant cardiac hemodynamic response to NEP-I was a decrease in right atrial pressure observed at one hour post-NEP-I. In addition, a significant increase in plasma ANF was observed after NEP-I administration $(524 \pm 77$ to $680 \pm 104 \mathrm{pg} / \mathrm{ml})$, which returned towards baseline levels $1 \mathrm{~h}$ post-NEP-I. Plasma cGMP levels paralleled this response. Sustained decreases in tubular sodium reabsorption were observed after NEP-I administration in group I, as indicated by increases in fractional excretion of sodium and decreases in distal fractional sodium reabsorption. However, there were no significant renal hemodynamic responses to NEP-I.

In group II with CHF and inhibition of AII generation, there were no initial systemic hemodynamic responses to NEPI administration, but a small decrease in cardiac output and increased systemic vascular resistance were observed $1 \mathrm{~h}$ postNEP-I. In addition, a significant increase in plasma ANF was observed after NEP-I in group II ( $346 \pm 63$ to $447 \pm 71 \mathrm{pg} / \mathrm{ml})$, and plasma ANF levels tended to remain increased at $1 \mathrm{~h}$ postNEP-I administration. Plasma cGMP levels increased initially after NEP-I then returned to baseline levels. In contrast to group I, significant renal hemodynamic changes were observed in the CHF group with CEI after NEP-I administration. Specifically, a $58.7 \%$ increase in GFR, a 9.9\% decrease in renal blood flow, and a $91.7 \%$ increase in filtration fraction were observed in group II, and these changes tended to be sustained. Increases in urine flow, absolute sodium excretion, and fractional excre-

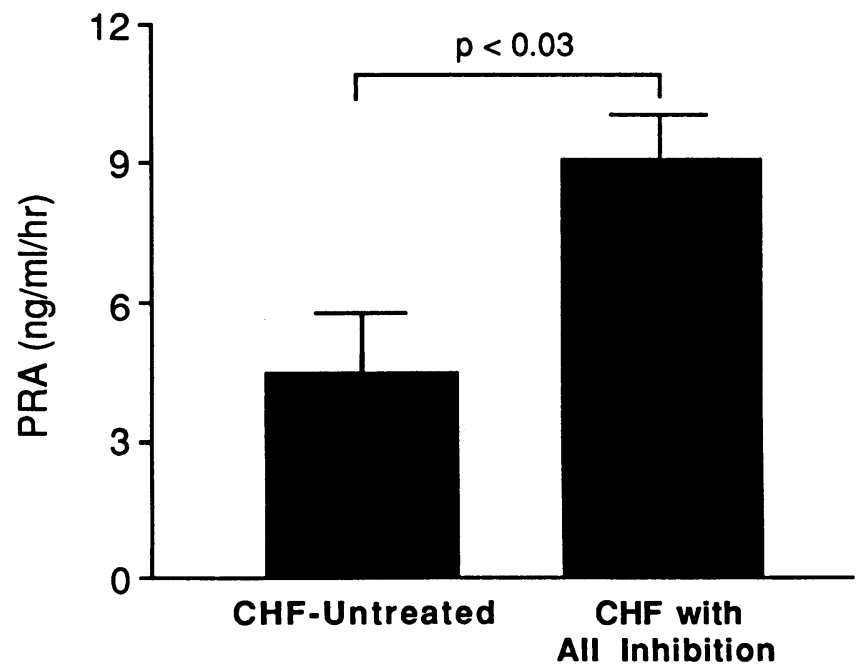

Figure 1. Baseline plasma renin activity in dogs with untreated $\mathrm{CHF}$ and dogs with $\mathrm{CHF}$ and AII inhibition with low dose captopril treatment. Data presented as mean \pm SEM. $n=6$ in each group.
Table I. Systemic Hemodynamic and Hormonal Function before and after Neutral Endopeptidase Inhibition

\begin{tabular}{|c|c|c|c|}
\hline & Pre-NEP-I & $\begin{array}{l}15-45 \min \\
\text { post-NEP-I }\end{array}$ & $\begin{array}{l}45-75 \min \\
\text { post-NEP-I }\end{array}$ \\
\hline \multicolumn{4}{|c|}{$\begin{array}{l}\text { Group I: Untreated CHF } \\
\quad(n=6)\end{array}$} \\
\hline MAP $(m m H g)$ & $98 \pm 3$ & $96 \pm 4$ & $92 \pm 3^{*}$ \\
\hline $\operatorname{RAP}(m m H g)$ & $4.7 \pm 0.6$ & $4.0 \pm 0.4$ & $2.8 \pm 0.8^{*}$ \\
\hline PCWP $(m m H g)$ & $19.9 \pm 2.3$ & $19.2 \pm 1.7$ & $16.6 \pm 0.7$ \\
\hline $\mathrm{CO}$ (liters/min) & $1.5 \pm 0.1$ & $1.3 \pm 0.1$ & $1.2 \pm 1.0$ \\
\hline $\operatorname{SVR}(R U)$ & $63 \pm 6$ & $73 \pm 6$ & $72 \pm 3$ \\
\hline ANF $(p g / m l)$ & $524 \pm 77$ & $680 \pm 104^{*}$ & $555 \pm 49$ \\
\hline cGMP $(\mathrm{pmol} / \mathrm{ml})$ & $12.8 \pm 2.4$ & $23.4 \pm 5.5^{*}$ & $16.9 \pm 4.3$ \\
\hline PRA $(n g / m l$ per $h)$ & $2.8 \pm 1.2$ & $2.6 \pm 1.2$ & $3.7 \pm 1.8$ \\
\hline $\operatorname{ALDO}(n g / d l)$ & $58 \pm 31$ & $54 \pm 31$ & $58 \pm 37$ \\
\hline \multicolumn{4}{|l|}{$\begin{array}{c}\text { Group II: CHF with All } \\
\text { Inhibition }(n=6)\end{array}$} \\
\hline MAP $(m m H g)$ & $93 \pm 11$ & $92 \pm 4$ & $90 \pm 2$ \\
\hline $\mathrm{RAP}(m m H g)$ & $6.2 \pm 1.7$ & $5.0 \pm 1.5$ & $4.3 \pm 1.6$ \\
\hline PCWP $(m m H g)$ & $18.7 \pm 1.7$ & $18.7 \pm 1.6$ & $17.8 \pm 2.4$ \\
\hline $\mathrm{CO}$ (liters/min) & $1.3 \pm 0.1$ & $1.3 \pm 0.1$ & $1.1 \pm 0.1^{*}$ \\
\hline $\operatorname{SVR}(R U)$ & $66 \pm 7$ & $67 \pm 8$ & $83 \pm 11^{*}$ \\
\hline $\mathrm{ANF}(p g / m l)$ & $346 \pm 63^{\ddagger}$ & $447 \pm 71^{*}$ & $448 \pm 119$ \\
\hline cGMP $(\mathrm{pmol} / \mathrm{ml})$ & $14.3 \pm 2.6$ & $20.5 \pm 3.1^{*}$ & $16.3 \pm 3.2$ \\
\hline PRA $(n g / m l / h)$ & $5.4 \pm 1.2$ & $3.0 \pm 0.7$ & $6.1 \pm 1.4$ \\
\hline $\operatorname{ALDO}(n g / d l)$ & $22 \pm 10$ & $18 \pm 6$ & $20 \pm 7$ \\
\hline
\end{tabular}

All data expressed as mean \pm SEM.

${ }^{*} P<0.05$ vs. baseline; ${ }^{\ddagger} P<0.05$ vs. CHF untreated.

MAP, mean arterial pressure; RAP, right atrial pressure; PCWP, pulmonary capillary wedge pressure; $C O$, cardiac output; SVR, systemic vascular resistance; $R U$, resistance units $(\mathrm{mmHg} / \mathrm{ml}$ per $\mathrm{min}$ ); PRA, plasma renin activity; cGMP, plasma cyclic GMP; ALDO, plasma aldosterone.

tion of sodium were observed in Group II in association with significant increases in fractional excretion of ANF and decreases in distal fractional sodium reabsorption. The GFR, filtration fraction, absolute sodium excretion, and distal fractional sodium reabsorption responses to NEP-I in the CHF group with CEI were significantly greater than the responses to NEP-I in the untreated animals with CHF (Fig. 2).

In the CHF group with inhibition of endogenous AII generation, low dose intrarenal AII infusion had marked effects upon the initial renal responses to NEP-I as shown in Fig. 3. In the AII kidney, there was no GFR or filtration fraction response to NEP-I as was observed in the control kidney. In addition to the consequent reductions in filtered load of sodium, there was a significantly smaller decrease in distal nephron sodium reabsorption in the AII infused kidney.

\section{Discussion}

The present studies were designed to test the hypothesis that chronic inhibition of AII generation during the evolution of experimental CHF potentiates the renal actions of NEP-I. These studies demonstrate that the renal natriuretic responses to NEP-I in experimental CHF are significant. However, in the same experimental model of CHF, chronic inhibition of AII generation with converting enzyme inhibition in the absence of significant changes in systemic hemodynamics or renal func- 
Table II. Renal Hemodynamic and Excretory Function before and after Neutral Endopeptidase Inhibition

\begin{tabular}{|c|c|c|c|}
\hline & Pre-NEP-I & $\begin{array}{l}15-45 \mathrm{~min} \\
\text { post-NEP-I }\end{array}$ & $\begin{array}{l}45-75 \mathrm{~min} \\
\text { post-NEP-I }\end{array}$ \\
\hline \multicolumn{4}{|l|}{$\begin{array}{l}\text { Group I: Untreated CHF } \\
\quad(n=6)\end{array}$} \\
\hline GFR $(\mathrm{ml} / \mathrm{min})$ & $20.2 \pm 3.8$ & $19.5 \pm 4.4$ & $17.6 \pm 3.4$ \\
\hline $\operatorname{RBF}(m l / m i n)$ & $102 \pm 13$ & $98 \pm 9$ & $97 \pm 6$ \\
\hline Filtration fraction & $0.34 \pm 0.09$ & $0.36 \pm 0.06$ & $0.33 \pm 0.06$ \\
\hline $\mathrm{UV}(\mathrm{ml} / \mathrm{min})$ & $0.41 \pm 0.32$ & $0.85 \pm 0.45$ & $0.54 \pm 0.15$ \\
\hline $\mathrm{UNaV}(\mu E q / \mathrm{min})$ & $29.3 \pm 19.2$ & $69.5 \pm 24.7$ & $56.0 \pm 31.7$ \\
\hline FENa (\%) & $0.86 \pm 0.41$ & $1.88 \pm 0.56^{*}$ & $1.65 \pm 0.74^{*}$ \\
\hline Prox FRNa (\%) & $70.1 \pm 5.3$ & $58.5 \pm 8.2$ & $65.2 \pm 8.0$ \\
\hline Dist FRNa (\%) & $97.6 \pm 1.0$ & $96.1 \pm 0.9^{*}$ & $96.3 \pm 1.2$ \\
\hline FE ANF (\%) & $0.03 \pm 0.01$ & $1.95 \pm 0.61^{*}$ & $1.43 \pm 0.42^{*}$ \\
\hline Renal cGMP ( pmol/min) & $600 \pm 257$ & $1117 \pm 418$ & $830 \pm 271$ \\
\hline \multicolumn{4}{|l|}{ Group II: CHF with All } \\
\hline GFR $(\mathrm{ml} / \mathrm{min})$ & $19.6 \pm 2.5$ & $31.1 \pm 4.0^{* \pm}$ & $27.8 \pm 5.4$ \\
\hline $\mathrm{RBF}(\mathrm{ml} / \mathrm{min})$ & $141 \pm 10$ & $127 \pm 12^{*}$ & $118 \pm 15^{*}$ \\
\hline Filtration Fraction & $0.24 \pm 0.03$ & $0.46 \pm 0.05^{*}$ & $0.42 \pm 0.06^{*}$ \\
\hline $\mathrm{UV}(\mathrm{ml} / \mathrm{min})$ & $0.30 \pm 0.15$ & $1.08 \pm 0.27^{*}$ & $0.68 \pm 0.48$ \\
\hline $\mathrm{UNaV}(\mu E q / \mathrm{min})$ & $41.6 \pm 15.6$ & $140.1 \pm 22.7^{*}$ & $74.3 \pm 12.4$ \\
\hline FENa (\%) & $1.44 \pm 0.61$ & $3.28 \pm 0.63^{*}$ & $2.06 \pm 0.45^{*}$ \\
\hline Prox FRNa (\%) & $53.7 \pm 9.4$ & $61.5 \pm 5.7$ & $74.4 \pm 2.6$ \\
\hline Dist FRNa (\%) & $96.0 \pm 1.9$ & $90.3 \pm 2.6^{* \pm}$ & $91.4 \pm 1.1^{* \neq}$ \\
\hline FE ANF (\%) & $0.24 \pm 0.18$ & $4.15 \pm 1.56^{*}$ & $3.94 \pm 1.96^{*}$ \\
\hline Renal cGMP ( pmol/min $)$ & $788 \pm 261$ & $1145 \pm 323$ & $777 \pm 239$ \\
\hline
\end{tabular}

All values presented are means \pm SEM.

$P<0.05$ vs. baseline; ${ }^{\ddagger} P<0.05$ vs. CHF-untreated.

$\mathrm{RBF}$, renal blood flow; UV, urine flow; FENa, fractional excretion of sodium; FE ANF, fractional excretion of atrial natriuretic factor; renal cGMP, net renal generation of cyclic GMP (see Methods for calculation).

tion at baseline, potentiated both renal hemodynamic and excretory responses to NEP-I. The potentiated renal hemodynamic response was associated with significant increases in GFR and filtration fraction which has not been observed previously in either normal subjects or in the setting of CHF. Finally, in the CHF group with CEI, an intrarenal infusion of low dose AII completely abolished the potentiated renal responses to NEP-I supporting the concept that intrarenal AII inhibition, rather than improved systemic hemodynamics or potentiation of other peptide systems, mediated the enhanced renal responses to NEP-I in group II.

We report, for the first time, the modulating role of the RAAS upon the renal actions of NEP-I in CHF. Importantly, the potentiating action of low dose inhibition of AII generation occurred despite a tendency towards reduced renal perfusion pressure, a parameter of profound functional importance for renal responses to ANF (5). Analogously, Abassi et al. (17) demonstrated that $C E I$ potentiated natriuretic responses to ANF in CHF despite significant decreases in renal perfusion pressure. Moreover, the observation that chronic inhibition of AII generation did not significantly alter systemic hemodynamics at baseline compared with untreated CHF suggests that potentiation of NEP-I action was not simply a consequence of reducing the hemodynamic severity of CHF. Nevertheless, we did observe a $34 \%$ reduction in plasma ANF levels in the CHF
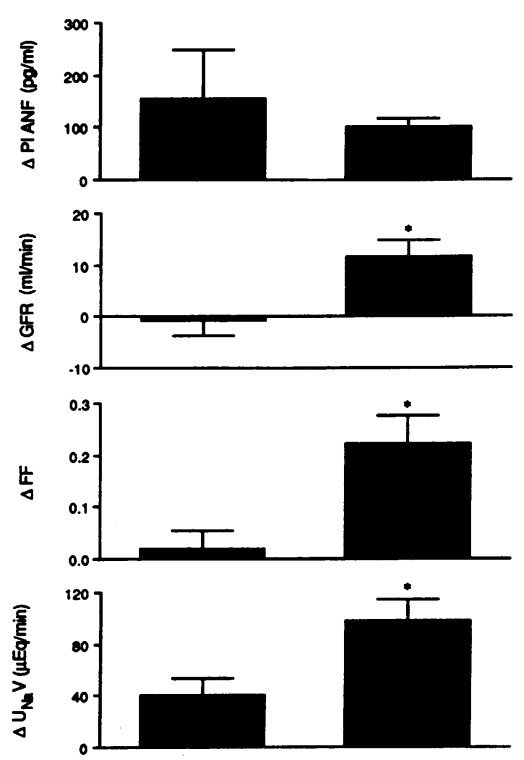

Figure 2. Responses to neutral endopeptidase inhibition (SQ 28,603, $30 \mathrm{mg} / \mathrm{kg}$ i.v.) in dogs with untreated $\mathrm{CHF}$ and dogs with CHF and AII

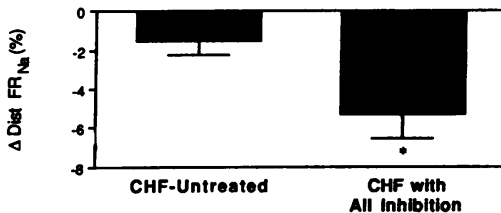
inhibition. Data presented are mean changes from baseline \pm SEM. $n=6$ in each group. ${ }^{*} P<0.05$ vs. untreated $\mathrm{CHF}$.

group with low dose CEI which is comparable to the reductions induced by a 20 -fold greater dose of CEI employed in preliminary studies by Villarreal and Freeman (15). The significant increase in plasma renin activity at baseline in the group treated with captopril supports a significant, though probably not complete, inhibition of angiotensin converting enzyme.
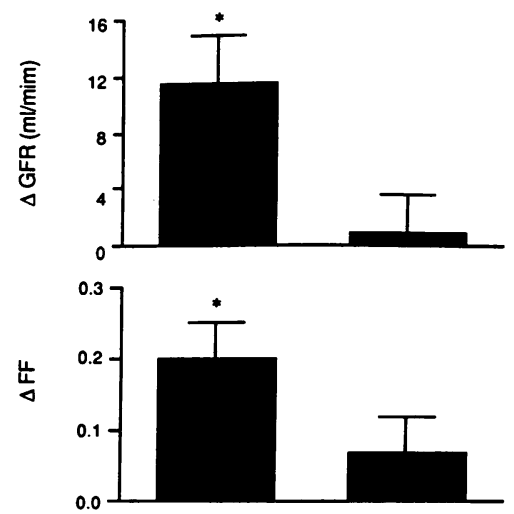

Figure 3. Comparison of responses to neutral endopeptidase inhibi-

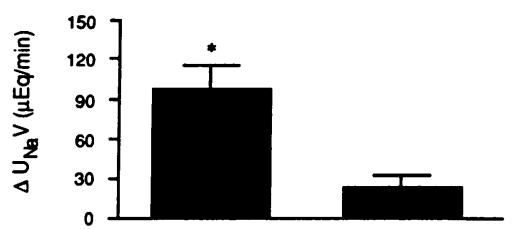
tion (SQ 28,603, 30 $\mathrm{mg} / \mathrm{kg}$ i.v.) in the presence of chronic AII inhibition with and without infusion of exogenous AII (1.5 ng/kg per min intrarenally). The vehicle kidney received an infusion of intrarenal $0.9 \%$ saline at $0.5 \mathrm{ml} /$ min. Data presented are mean changes from baseline \pm SEM. $n=6$. ${ }^{*} P<0.05$ vs. the AII kidney. 
Finally, our finding that inhibition of AII generation did not significantly alter baseline sodium excretion in severe CHF is consistent with some $(17)$ but not all $(7,29)$ previous studies, and again could reflect a partial degree of converting enzyme inhibition.

Despite the relatively lower plasma ANF levels in the captopril-treated animals with CHF, baseline plasma cGMP levels did not differ between the two groups. One possible explanation is that the renin angiotensin aldosterone system activation in CHF is impairing cGMP generation in congestive heart failure. In fact, a recent study (13) demonstrates that despite steadily increasing plasma ANF concentrations, plasma cGMP levels plateau during the evolution of experimental heart failure in association with progressive increases in plasma renin activity. Moreover, an elegant in vitro study by Smith and Lincoln (30) demonstrates that angiotensin II mediated increases in intracellular phophodiesterases may impair ANF mediated increases in cyclic GMP. Thus, it is conceivable that the increased ratio of plasma ANF to plasma cyclic GMP before NEP-I in group II is related to attenuation of angiotensin II generation by captopril.

The enhanced natriuretic response to NEP-I in CHF with inhibition of AII generation is consistent with the concept that the renal actions of NEP-I, like those of ANF, are antagonized by activation of the RAAS in CHF. The multilevel antinatriuretic effects of AII are well established and include direct or indirect effects on multiple nephron segments (31). In recent years, a multilevel functional antagonism between the RAAS and ANF has emerged, particularly with respect to sodium excretion. Studies by Appel et al. (32) demonstrate that ANF, and its intracellular second messenger cGMP, dose-dependently antagonize AII-mediated mesangial cell contraction. In addition, Showalter et al. (16) observed that low dose intrarenal AII attenuates ANF-mediated changes in both GFR and tubular sodium reabsorption in the normal dog, while the studies of Abassi et al. (17) indicate that CEI restores tubular responses to ANF in rats with CHF. Studies by Salazar et al. (33) suggest that AII antagonizes ANF induced decreases in proximal tubule reabsorption. In the present studies potentiation of the natriuretic actions of NEP-I with inhibition of AII generation occurred in the absence of any decreases in whole kidney proximal fractional sodium reabsorption, as determined by lithium clearance, suggesting that CEI did not potentiate NEP-I induced natriuresis at the level of the proximal tubule.

We observed that CEI greatly potentiated the renal hemodynamic actions of NEP-I. In previous studies, NEP-I produced no significant changes in whole kidney renal hemodynamics in normal animals (22) or in those with untreated CHF (12). However, in the presence of chronic CHF and inhibition of the generation of AII, marked increases in GFR and filtration fraction and modest decreases in renal blood flow were observed. Recent studies demonstrating that the renal effects of NEP-I are virtually abolished in the presence of monoclonal anti-ANF antibodies (34), support the concept that the renal actions of NEP-I are largely mediated via ANF potentiation. Consequently, the known renal hemodynamic actions of ANF suggest several possible mechanisms for the potentiated renal hemodynamic effects of NEP-I in CHF with CEI. As ANF attenuates and AII enhances whole kidney tubuloglomerular feedback responses $(35,36)$, inhibition of AII might potentiate ANF- or NEP-I-mediated increases in GFR via tubuloglomerular feedback inhibition. This mechanism may be particularly important in CHF where GFR responses to increases in distal nephron solute delivery are intact or even accentuated $(35,37)$. In addition, ANF increases GFR and filtration fraction via decreases in afferent arteriolar resistance and increases in efferent arteriolar resistance (38). The latter effect upon efferent resistance may be enhanced in the presence of inhibition of AII which should decrease basal efferent tone (39). Alternatively, because ANF increases GFR via inhibition of AII-induced mesangial cell contraction (32) AII inhibition might potentiate this response. Finally, because neutral endopeptidase may participate in the degradation of angiotensins (40), NEP-I might potentiate the actions of both ANF and AII simultaneously. From this perspective, treatment with CEI prevents compensatory or counterregulatory increases in renal AII activity following administration of NEP-I in CHF.

Chronic inhibition of AII generation also potentiated the tubular actions of NEP-I in experimental CHF. As with the renal hemodynamic responses to NEP-I, the potentiation of NEP-I action on distal fractional sodium reabsorption by CEI in the present studies is consistent with potentiation of the known actions of ANF at the inner medullary collecting duct. Because AII is known to decrease medullary blood flow (41), AII inhibition might increase medullary blood flow and secondarily augment the distal nephron responses to ANF. Alternatively, to the extent that AII opposes ANF mediated cGMP accumulation in inner medullary collecting duct cells, as it does in vascular smooth muscle (30), AII inhibition might potentiate ANF-mediated natriuresis at the collecting duct, particularly in CHF with activation of the intrarenal RAAS. Finally, insofar as specific AII receptors have been demonstrated within several distal nephron segments (42), it is conceivable that CEI potentiated distal nephron responses to NEP-I by antagonizing direct effects of AII on epithelial transport. Studies to date, however, neither support nor refute a direct physiologic action of AII upon epithelial transport beyond the proximal tubule.

An additional mechanism which could have contributed to the enhanced distal nephron actions of NEP-I in the current studies relates to the action of CEI upon aldosterone. Specifcally, because aldosterone stimulated sodium reabsorption at the level of the collecting duct might limit the distal nephron natriuretic effects of NEP-I in CHF, aldosterone antagonism consequent to CEI may have contributed to the enhanced decreases in distal fractional sodium reabsorption observed in group II. However, the reversal of this enhanced tubular response with low dose intrarenal AII suggests that aldosterone antagonism does not fully account for the effects of CEI upon distal nephron natriuretic responses to NEP-I in CHF.

In both experimental groups significant increases in fractional excretion of ANF were observed following NEP-I in association with increases in distal fractional reabsorption of sodium. These observations support the concept that blocking proximal degradation of ANF with NEP-I allows intact ANF to reach the distal nephron $(11,34)$, specifically the inner medullary collecting duct where ANF receptors are abundant (43). Recent studies by Sonnenberg et al. (44) demonstrating that intraluminal ANF modulates distal nephron sodium transport lends further support to this concept. From this perspective, probable increases in filtered ANF as a consequence of the potentiated GFR effects of NEP-I by AII inhibition, may have contributed to distal nephron potentiation of NEP-I by allowing even greater distal nephron delivery of ANF. In fact, increases in fractional excretion of ANF after NEP-I tended to be greatest in group II where significant renal hemodynamic effects of NEP-I were observed. 
The NEP-I used in this study, SQ 28,603, has minimal activity against other proximal tubule brush border enzymes; however, neutral endopeptidase itself hydrolyzes several peptides other than ANF in vitro, including kinins, angiotensins, enkephalins, neurotensin, substance $P$, insulin B-chain, and endothelin (45). Because angiotensin converting enzyme degrades kinins in vivo, the renal and systemic actions of kinins might be doubly potentiated by NEP-I in the presence of chronic CEI. In regard to these theoretical considerations and recent studies by Smits et al. (46) suggesting that kinins participate in the potentiation of ANF activity by NEP-I, we cannot exclude a role for kinins in the potentiated renal responses to NEP-I in the CHF group with AII inhibition. Similarly, although renal blood flow was not significantly different in groups I and II before NEP-I, we cannot exclude that a vasodilator effect independent of AII antagonism contributed to the enhanced renal responses. Nevertheless, in group II, the reversal of all potentiated renal responses to NEP-I with low dose intrarenal AII supports the concept that the potentiated renal hemodynamic and tubular responses to NEP-I in CHF were primarily related to AII inhibition rather than kinin potentiation or nonspecific hemodynamic alterations.

In conclusion, the present studies confirm previous investigations by demonstrating that, in anesthetized dogs in the presence of experimental CHF, the natriuretic effects of NEP-I occur principally via decreases in tubular sodium reabsorption independent of significant alterations in GFR or renal blood flow. The present studies extend previous investigations by demonstrating that, in moderately severe $\mathrm{CHF}$, chronic inhibition of AII generation potentiates the renal hemodynamic and tubular responses to NEP-I in CHF. Finally, low dose intrarenal AII abolished the potentiated responses to NEP-I suggesting that AII inhibition, rather than systemic hemodynamic factors or modulation of other peptide systems, participate in the enhanced renal responses to NEP-I in CHF treated with chronic converting enzyme inhibition. Because chronic converting enzyme inhibition has proven efficacious in humans with moderately severe CHF (47), these studies suggest a possible therapeutic role for adjuvant therapy with NEP-I in human $\mathrm{CHF}$ associated with renal decompensation. decompensation.

\section{Acknowledgments}

The authors gratefully acknowledge the technical assistance of Larry L. Aarhus and Denise M. Heublien.

This research was supported by grants HL-36634 and HL-0711 from the National Institutes of Health, and from the Bristol-MyersSquibb Institute for Medical Research, and the Mayo Foundation. Dr. Margulies was supported by the N.I.H. Training Grant in Cardiovascular Research HL-07111-14, Dr. Perrella was supported by the N.I.H. Multidisciplinary Training Grant in Hypertension HL-07269, and Dr. Burnett is an Established Investigator of the American Heart Association. SQ 28,603 was generously supplied by Dr. Nick Trippodo of the Bristol-Myers-Squibb Institute for Medical Research, Princeton, NJ.

\section{References}

1. Burnett, J. C., Jr., P. C. Kao, D. C. Hu, D. W. Heser, D. Heublein, J. P. Granger, T. J. Opgenorth, and G. S. Reeder. 1986. Atrial natriuretic peptide elevation in congestive heart failure in the human. Science (Wash. DC). 231:1145-1147.

2. Cody, R. J., S. A. Atlas, J. H. Laragh, S. H. Kubo, A. B. Covit, K. S. Ryman, A. Shaknovich, K. Pondolfina, M. Clark, M. J. F. Camargo, et al. 1986. Atrial natriuretic factor in normal subjects and heart failure patients. J. Clin. Invest. 78:1362-1374.

3. Crozier, I. G., H. Ikram, H. J. Gomez, M. G. Nicholls, E. A. Espiner, and N. J. Warner. 1986. Haemodynamic effects of atrial peptide infusion in heart failure. Lancet. ii:1242-1245.

4. Koepke, J. P., and G. F. DiBona. 1987. Blunted natriuresis to atrial natriuretic peptide in chronic sodium-retaining disorders. Am. J. Physiol. 252:F865F871.

5. Redfield, M. M., B. S. Edwards, D. M. Heublein, and J. C. Burnett, Jr. 1989. Restoration of renal response to atrial natriuretic factor in experimental low-output heart failure. Am. J. Physiol. 257:R917-R923.

6. Saito, Y. M., K. M. P. Nakao, K. M. Nishimura, A. M. Sugawara, K. M. P. Okumura, K. M. Obata, R. M. Sonoda, T. M. P. Ban, H. M. P. Yasue, and H. M. P. Imura. 1987. Clinical application of atrial natriuretic polypeptide in patients with congestive heart failure: beneficial effects on left ventricular function. Circulation. 76:115-124.

7. Winaver, J., A. Hoffman, J. C. Burnett, Jr., and A. Haramati. 1988. Hormonal determinants of sodium excretion in rats with experimental high-output heart failure. Am. J. Physiol. 254:R776-R784.

8. Ballerman, B. J., R. L. Hoover, M. J. Karnovsky, and B. M. Brenner. 1985. Physiologic regulation of atrial natriuretic peptide receptors in rat renal glomeruli. J. Clin. Invest. 76:2049-2056.

9. Cachofeiro, C., E. L. Schiffrin, G. Jasmin, M. Cantin, and R. Garcia. 1989. Glomerular and vascular atrial natriuretic factor (ANF) receptors in experimental heart failure (CHF). Circulation. 80:II-1 12. (Abstr.)

10. Ganquelin, G., R. Garcia, F. Carrier, M. Cantin, J. Gutkowski, G. Thibault, and E. L. Schriffrin. 1988. Glomerular ANF receptor regulation during changes in sodium and water metabolism. Am. J. Physiol. 254:F51-F55.

11. Perrella, M. A., K. B. Margulies, C. M. Wei, L. L. Aarhus, D. M. Heublein, and J. C. Burnett, Jr. 1991. Pulmonary and urinary clearance of atrial natriuretic factor in acute congestive heart failure. J. Clin. Invest. 87:1649-1655.

12. Cavero, P. G., K. B. Margulies, J. M. Winaver, A. A. Seymour, N. G. Delaney, and J. C. Burnett, Jr. 1990. Cardiorenal actions of neutral endopeptidase inhibition in experimental congestive heart failure. Circulation. 82:196-201.

13. Margulies, K. B., D. M. Heublein, and J. C. Burnett, Jr. 1991. ANF-mediated renal cyclic GMP generation in congestive heart failure. Am. J. Physiol. 260:F562-F568.

14. Slick, G. L., G. F. DiBona, and G. L. Kaloyanides. 1974. Renal sympathetic nerve activity in sodium retention of acute caval constriction. Am. J. Physiol. 226:925-932.

15. Villarreal, D., and R. H. Freeman. 1989. Captopril restores the renal responsiveness to synthetic atrial natriuretic factor in dogs with heart failure. Circulation. 80:II-112. (Abstr.)

16. Showalter, C. J., R. S. Zimmerman, T. R. Schwab, B. S. Edwards, T. J. Opgenorth, and J. C. Burnett, Jr. 1988. Renal response to atrial natriuretic factor is modulated by intrarenal angiotensin II. Am. J. Physiol. 254:R453-R456.

17. Abassi, Z., A. Haramati, A. Hoffman, J. C. Burnett, Jr., and J. Winaver. 1990. Effect of converting-enzyme inhibition on renal response to ANF in rats with experimental heart failure. Am. J. Physiol. 259:R84-R89.

18. Raya, T. E., R. W. Lee, T. B. Westhoff, and S. M. Goldman. 1989. Captopril restores hemodynamic responsiveness to atrial natriuretic peptide in rats with heart failure. Circulation. 80:1886-1892.

19. Maher, E., P. Cernacek, and M. Levy. 1989. Heterogeneous renal responses to atrial natriuretic factor. I. Chronic caval dogs. Am. J. Physiol. 257:R1057-R1067.

20. Berg, J. A., M. Hayashi, Y. Fujii, and A. I. Katz. 1988. Renal metabolism of atrial natriuretic peptide in the rat. Am. J. Physiol. 255:F466-F473.

21. Erdos, E. G., and R. A. Skidgel. 1989. Neutral endopeptidase 24.11 (enkephalinase) and related regulators of peptide hormones. FASEB (Fed. Am. Soc. Exp. Biol.) J. 3:145-151.

22. Margulies, K. B., P. Cavero, A. Seymour, N. Delaney, and J. J. Burnett. 1990. Neutral endopeptidase inhibition (NEP-I) enhances natriuresis via renal tubular mechanisms. Kidney Int. 38:67-72.

23. Riegger, G. A. J., D. M. Elsner, E. P. Kromer, C. Daffner, W. G. Forssmann, F. Muders, E. W. Pascher, and K. M. Kochsiek. 1988. Atrial natriuretic peptide in congestive heart failure in the dog: plasma levels, cyclic guanosine monophosphate, ultrastructure of atrial myoendocrine cells, and hemodynamic, hormonal and renal effects. Circulation. 77:398-406.

24. Cavero, P. G., W. L. Miller, D. M. Heublein, K. B. Margulies, and J. C. Burnett, Jr. 1990. Endothelin in experimental congestive heart failure in the anesthetized dog. Am. J. Physiol. 259:F312-F317.

25. Fuhr, J. J., K. J. Kaczmarczyk, and C. D. Kruttgen. 1955. Eine einfache colorimetrische methode zur inulinbestimmung fur nieren-clearance-untersuchungen bei stoffwechselgesunden und diabetikern. Klin. Wochenschr. 33:729-730.

26. Haber, E., T. Koerner, L. B. Page, B. Kliman, and A. Purnode. 1969. Application of a radioimmunoassay for angiotensin I to the physiologic measurements of plasma renin activity in normal human subjects. J. Clin. Endocrinol. \& Metab. 29:1349-1355.

27. Zimmerman, R. S., J. A. Shirger, B. A. Edwards, T. R. Schwab, D. M. Heublein, and J. C. Burnett, Jr. 1987. Cardio-renal-endocrine dynamics during 
stepwise infusion of physiologic and pharmacologic concentrations of atrial natriuretic factor in the dog. Circ. Res. 61:63-69.

28. Steiner, A. L., A. S. Pagliara, L. R. Chase, and D. M. Kipnis. 1972 Radioimmunoassay for cyclic nucleotides. J. Biol. Chem. 247:1111-1120.

29. Freeman, R. H., J. O. Davis, G. M. Williams, J. M. DeForrest, A. A Seymour, and B. P. Rowe. 1979. Effects of the oral converting enzyme inhibitor, SQ 14225, in a model of low cardiac output in dogs. Circ. Res. 45:540-545.

30. Smith, J. B., and T. M. Lincoln. 1987. Angiotensin decreases cyclic GMP accumulation produced by atrial natriuretic factor. Am. J. Physiol. 253:C147C150.

31. Hall, J. E. 1986. Control of sodium excretion by angiotensin II: intrarenal mechanisms and blood pressure regulation. Am. J. Physiol. 250:R960-R972.

32. Appel, R. G., J. Wang, M. S. Simonson, and M. J. Dunn. 1986. A mechanism by which atrial natriuretic factor mediates its glomerular actions. $\mathrm{Am}$. J. Physiol. 251:F1036-F1042.

33. Salazar, F. J., J. P. Granger, M. J. Fiksen-Olsen, M. D. Bentley, and J. C. Romero. 1987. Possible modulatory role of angiotensin II on atrial peptide-induced natriuresis. Am. J. Physiol. 253:F880-F883.

34. Wilkins, M. R., S. L. Settle, P. T. Stockman, and P. Needleman. 1990. Maximizing the natriuretic effect of endogenous atriopeptin in a rat model of heart failure. Proc. Natl. Acad. Sci. USA. 87:6465-6469.

35. Margulies, K. B., and J. C. Burnett, Jr. 1990. Atrial natriuretic factor modulates whole kidney tubuloglomerular feedback. Am. J. Physiol. 259:R97R101.

36. Mitchell, K. D., and G. Navar. 1988. Enhanced tubuloglomerular feedback during peritubular infusions of angiotensins I and II. Am. J. Physiol. 255:F383-F390.

37. Heidemann, H. T., E. K. Jackson, J. F. Gerkins, and R. A. Branch. 1987.
Intrarenal hypertonic saline infusions in dogs with thoracic caval constriction. Kidney Int. 32:488-492.

38. Dunn, B. R., I. Ichikawa, J. M. Pfeffer, J. L. Troy, and B. M. Brenner 1986. Renal and systemic hemodynamic effects of synthetic atrial natriuretic peptide in the anesthetized rat. Circ. Res. 559:237-246.

39. Levens, N. R., M. J. Peach, and R. M. Carey. 1981. Role of the intrarena renin-angiotensin system in the control of renal function. Circ. Res. 48:157-167.

40. Kenny, A. J., and S. L. Stephenson. 1988. Role of endopeptidase-24.11 in the inactivation of atrial natriuretic peptide. FEBS (Fed. Eur. Biochem. Soc.) Lett. 232:1-8.

41. Chou, S., P. F. Faubert, and J. G. Porush. 1986. Contribution of angiotensin to the control of medullary hemodynamics. Fed. Proc. 45:1438-1443.

42. Mujais, S. K., S. Kauffman, and A. I. Katz. 1986. Angiotensin II binding sites in individual segments of the rat nephron. J. Clin. Invest. 77:315-318.

43. Koseki, C., Y. Hayashi, S. Torikai, M. Furuya, N. Ohnuma, and M. Imai. 1986. Localization of binding sites for a-atrial natriuretic polypeptide in rat kidney. Am. J. Physiol. 250:F210-F216.

44. Sonnenberg, H., U. Honrath, and D. R. Wilson. 1990. In vivo microperfusion of inner medullary collecting duct in rats: effect of amiloride and ANF. Am. J. Physiol. 259:F222-F226.

45. Shimamori, Y., Y. Watanabe, and Y. Fujimoto. 1986. Specificity of a membrane-bound neutral endopeptidase from a rat kidney. Chem. Pharm. Bull. (Tokyo). 34:275-280.

46. Smits, G. J., D. E. McGraw, and A. J. Trapani. 1990. Interaction of ANP and bradykinin during endopeptidase 24.11 inhibition: renal effects. Am. J. Physiol. 258:F1417-F1424.

47. Consensus Trial Study Group. 1987. Effects of enalapril on mortality in severe congestive heart failure. N. Engl. J. Med. 316:1429-1435. 